\title{
Influence of spinal cord injury on cerebral sensorimotor systems: a PET study
}

\author{
U Roelcke, A Curt, A Otte, J Missimer, R P Maguire, V Dietz, K L Leenders
}

\begin{abstract}
Objectives-To assess the effect of a transverse spinal cord lesion on cerebral energy metabolism in view of sensorimotor reorganisation.

Methods-PET and ${ }^{18}$ F-fluorodeoxyglucose were used to study resting cerebral glucose metabolism in 11 patients with complete paraplegia or tetraplegia after spinal cord injury and 12 healthy subjects. Regions of interest analysis was performed to determine global glucose metabolism (CMRGlu). Statistical parametric mapping was applied to compare both groups on a pixel by pixel basis (significance level $P=0 \cdot 001$ ).

Results-Global absolute CMRGlu was lower in spinal cord injury (33.6 (6.6) $\mu \mathrm{mol} / 100 \mathrm{ml} / \mathrm{min}$ (mean (SD)) than in controls (45.6 (6.2), Mann-Whitney $P=$ $0.0026)$. Statistical parametric mapping analysis disclosed relatively increased glucose metabolism particularly in the supplementary motor area, anterior cingulate, and putamen. Relatively reduced glucose metabolism in patients with spinal cord injury was found in the midbrain, cerebellar hemispheres, and temporal cortex.

Conclusions-It is assumed that cerebral deafferentiation due to reduction or loss of sensorimotor function results in the low level of absolute global CMRGlu found in patients with spinal cord injury. Relatively increased glucose metabolism in brain regions involved in attention and initiation of movement may be related to secondary disinhibition of these regions.
\end{abstract}

$(\mathcal{F}$ Neurol Neurosurg Psychiatry 1997;62:61-65) Scherrer Institute, Switzerland

U Roelcke

A Otte

J Missimer

R P Maguire

$\mathrm{K}$ L Leenders

Paraplegic Centre, University Hospital Balgrist, CH-8008

Zürich, Switzerland

A Curt

V Dietz

Department of

Neurology, University

Hospital, CH-8091

Zürich, Switzerland

K L Leenders

Correspondence to:

Professor Dr KL Leenders,

PET Program, Paul Scherre

Institute, $\mathrm{CH} 5232$ Villigen,

Switzerland.

Received 9 April 1996

and in revised form

23 July 1996

Accepted 20 August 1996

Table 1 Clinical data of patients with spinal cord injury
Keywords: spinal cord injury; cerebral sensorimotor systems; positron emission tomography

Spinal cord injury may damage descending or ascending corticospinal tracts. ${ }^{1}$ Depending on the level and extent of damage, patients may present with incomplete or complete loss of sensorimotor function of two or all four limbs. Whereas some patients recover from neurological deficit with time, other patients have persisting paraplegia or tetraplegia. ${ }^{2}$

The relevance of loss of sensorimotor function for the reorganisation of cerebral sensorimotor systems is not well understood. Clinical and neurophysiological studies provide evidence for reorganisation of the primary motor and sensory cortex in patients with spinal cord injury $^{345}$ or amputees. ${ }^{6}$ However, the relation between cerebral reorganisation within these regions and neuronal activity of functionally associated brain areas is not known. In the present study, we used PET and the tracer ${ }^{18} \mathrm{~F}$-fluorodeoxyglucose to study regional cerebral glucose metabolism, which is a measure of regional synaptic activity. ${ }^{78}$ With this method it has been shown that circumscribed brain lesions may suppress glucose metabolism or blood flow of functionally related remote brain areas. ${ }^{9}$ Accordingly, we assumed that the deafferentation state after spinal cord injury may be followed by an altered pattern of cerebral glucose metabolism in paraplegic and tetraplegic patients.

\section{Patients and methods}

11 right handed patients with spinal cord injury (nine men, two women, seven paraplegic, four tetraplegic patients (mean (SD) age 31 (11) years, range $19-53$ years) were

\begin{tabular}{|c|c|c|c|c|c|c|c|c|}
\hline $\begin{array}{l}\text { Patient } \\
\text { No }\end{array}$ & Paraltetra & Age (y) & Sex & $\begin{array}{l}\text { Interval } \\
\text { (months) }\end{array}$ & $\begin{array}{l}\text { Lesion } \\
\text { (rad) }\end{array}$ & $\begin{array}{l}\text { Motor } \\
\text { complete }\end{array}$ & $\begin{array}{l}\text { Sensory } \\
\text { complete }\end{array}$ & Medication \\
\hline $\begin{array}{r}1 \\
2 \\
3 \\
4 \\
5 \\
6 \\
7 \\
8 \\
9 \\
10 \\
11\end{array}$ & $\begin{array}{l}\text { Para } \\
\text { Para } \\
\text { Para } \\
\text { Para } \\
\text { Para } \\
\text { Para } \\
\text { Para } \\
\text { Tetra } \\
\text { Tetra } \\
\text { Tetra } \\
\text { Tetra }\end{array}$ & $\begin{array}{l}21 \\
22 \\
30 \\
34 \\
53 \\
41 \\
44 \\
19 \\
23 \\
24 \\
33\end{array}$ & $\begin{array}{l}M \\
F \\
F \\
M \\
M \\
M \\
M \\
M \\
M \\
M \\
M\end{array}$ & $\begin{array}{r}28 \\
9 \\
10 \\
6 \\
182 \\
190 \\
65 \\
22 \\
5 \\
56 \\
37\end{array}$ & $\begin{array}{l}\text { Th6 } \\
\text { L1/L2 } \\
\text { Th11/Th12 } \\
\text { L4 } \\
\text { C3/Th5 } \\
\text { Th4 } \\
\text { Th4/Th5 } \\
\text { C6 } \\
\text { C5/C6 } \\
\text { C5/C6 } \\
\text { C6/C7 }\end{array}$ & $\begin{array}{l}\text { Th6 } \\
\text { L2 } \\
\text { Th12 } \\
\text { L5 } \\
\text { Th3 } \\
\text { Th6 } \\
\text { Th5 } \\
\text { Th3^ } \\
\text { C6 } \\
\text { C7 } \\
\text { C7 }\end{array}$ & $\begin{array}{l}\text { Th9 } \\
\text { L4 } \\
\text { L1 } \\
\text { S3 } \\
\text { Th7 } \\
\text { Th6 } \\
\text { Th5 } \\
\text { Th3* } \\
\text { C8 } \\
\text { V7 } \\
\text { Th9 }\end{array}$ & $\begin{array}{l}\text { Bac, Clon } \\
\text { Mid, Oxy } \\
\text { Mid, Oxy } \\
\text { Cbz } \\
\text { Bac, Oxy } \\
\text { None } \\
\text { None } \\
\text { Clon } \\
\text { Clon } \\
\text { None } \\
\text { Bac }\end{array}$ \\
\hline
\end{tabular}

Interval = time interval between spinal cord injury and PET study; lesion (rad) = (upper/lower) level of radiologically documented vertebral damage; motor/sens complete $=$ highest spinal segment of complete loss of sensorimotor function; Bac $=$ baclofen; Clon = clonazepam; Mid = midodrin; Oxy = oxybutinin; $\mathrm{Cbz}=$ carbamazepin. ${ }^{\star}$ In this patient, bilaterally impaired motor and sensory function was present between $\mathrm{C} 7$ and $\mathrm{T} 2$, complete loss of function was present below $\mathrm{T} 3$. 
Sagittal

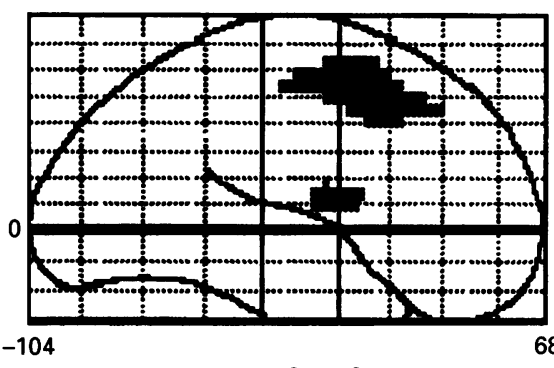

VPC VAC

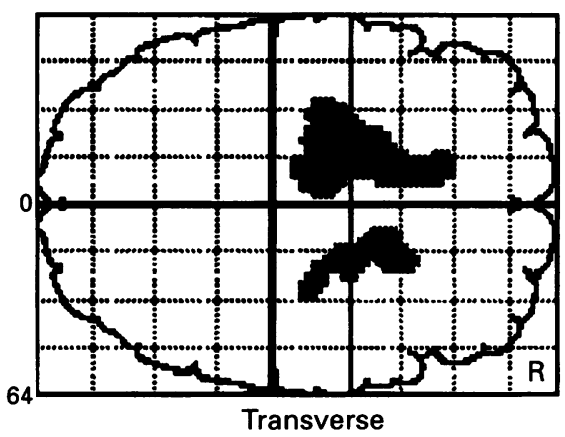

B

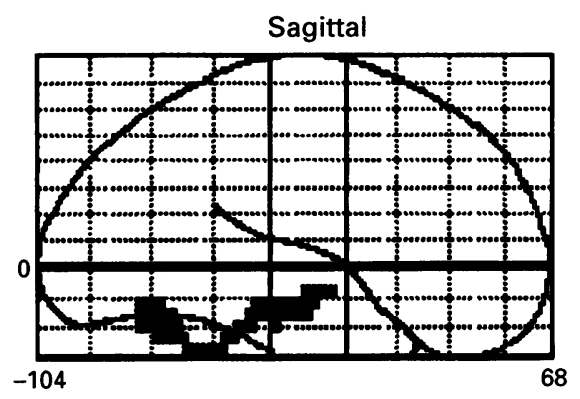

VPC VAC

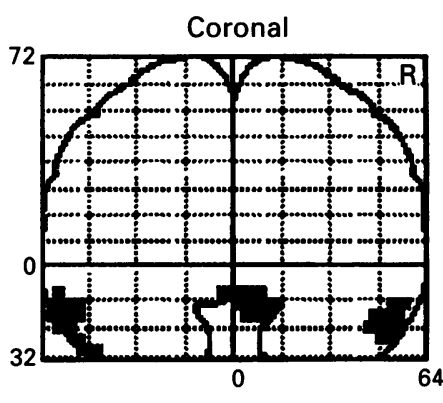

Association impairment scale. ${ }^{1}$ According to this scale, paraplegia or tetraplegia was complete in each patient (no motor or sensory function is preserved below the neurological level and extends through S4-S5). From the clinical status and CT of the brain which was performed on the day of the accident, there was no evidence for additional brain injury. Dysaesthetic pain was present in one patient (4) but was satisfactorily treated with carbamazepine. For comparison, 12 right handed healthy subjects were studied (age 34 (11), range 23 to 61 years). The study was approved by the ethics committee of the University Hospital Balgrist.

DATA ACQUISITION

FDG PET was performed with a 933/04-16 tomograph (CTI, Knoxville, four rings, seven planes, $8 \mathrm{~mm}$ full width at half maximum (FWHM). The FDG was prepared as previously described. ${ }^{10}$ The head of a subject was positioned parallel to the orbitomeatal line and was placed in an individually moulded thermoplastic head support to minimise movement during scanning. After two 10 minute transmission scans with a $68 \mathrm{Ga} / 68 \mathrm{Ge}$ ring source, 140 to $298 \mathrm{MBq}$ FDG were given intravenously over three minutes with a constant infusion pump. Twenty four arterial blood samples were manually drawn from an indwelling catheter for determination of plasma radioactivity and glucose concentration. A scan protocol comprising one dynamic (16 time frames, 48 minutes) and one static (five minutes) emission scan was used, covering the whole brain at two positions and yielding a total of 14 adjacent planes with a plane to plane distance of $8 \mathrm{~mm}$. With an autoradiographic method, ${ }^{11}$ the cerebral metabolic rate of glucose (CMRGlu; $\mu \mathrm{mol} / 100 \mathrm{ml} / \mathrm{min}$ ) was calculated for both data sets, which were combined to form a contiguous volume of 14 planes, $11.2 \mathrm{~cm}$ field of view. With statistical parametric mapping 95 , these slices were then interpolated to 26 planes of the standard stereotactic atlas coordinate system of Talairach and Tournoux. ${ }^{12}$

\section{STATISTICAL PARAMETRIC MAPPING}

This method has been described in detail by Friston et al. ${ }^{13}$ Briefly, after transformation to the stereotactic coordinate system, images were smoothed in 3D with a Gaussian filter with FWHM corresponding to the spatial resolution of the scanner $(8 \mathrm{~mm})$. Interindividual variations of global CMRGlu were accounted for by normalising individual global CMRGlu to an arbitrary mean (in our study $40 \mu \mathrm{mol} /$ $100 \mathrm{ml} / \mathrm{min}$ ) using an analysis of covariance (ANCOVA). Normalised images of patients with spinal cord injury and healthy subjects were compared by computing a pixel by pixel $t$ statistic. The $t$ statistic was transformed to a normal statistic yielding a $Z$ score for each pixel. Pixels exceeding the significance level of $P=0.001$ are displayed in axial, sagittal, and coronal projections of a statistical parametric mapping. To test for a possible relation between time from spinal cord injury and 
Table 2 Differences of cerebral glucose metabolism in patients with spinal cord injury and healthy subjects displayed as a statistical parametric map with a significance level of $P=0.001$

\begin{tabular}{|c|c|c|c|c|}
\hline \multirow[b]{2}{*}{ Area } & \multicolumn{3}{|c|}{ Talairach coordinates of peak differences } & \multirow{2}{*}{$\begin{array}{l}Z \text { score of } \\
\text { peak difference }\end{array}$} \\
\hline & $x$ & $y$ & $z$ & \\
\hline \multicolumn{5}{|l|}{ SCI > Controls: * } \\
\hline SMA (L) & -20 & -4 & +52 & $4 \cdot 36$ \\
\hline SMA (R) & +20 & -4 & +52 & $2 \cdot 96$ \\
\hline Anterior cingulate (L) & -10 & +10 & +44 & $4 \cdot 01$ \\
\hline Anterior cingulate (R) & +20 & +18 & +40 & $3 \cdot 23$ \\
\hline Putamen (L) & -22 & -6 & +8 & 3.66 \\
\hline Putamen (R) & +20 & -2 & +12 & $3 \cdot 39$ \\
\hline Sensorimotor cortex (R) & +26 & -12 & +52 & $2 \cdot 96$ \\
\hline \multicolumn{5}{|l|}{ SCI < Controls: $†$} \\
\hline Midbrain (R) & +6 & -20 & -16 & $3 \cdot 84$ \\
\hline Cerebellar hemisphere (L) & -50 & -44 & -28 & $2 \cdot 69$ \\
\hline Cerebellar hemisphere $(\mathrm{R})$ & +52 & -64 & -20 & $3 \cdot 77$ \\
\hline Lateral temporal cortex (L) & -58 & -20 & -16 & 3.55 \\
\hline
\end{tabular}

CMRGlu, the normalised images of all patients with spinal cord injury were compared with the time interval between spinal cord injury and PET studies by ANCOVA (significance level $P=0.001$ ). It must be noted that-regarding the time intervalpatients clustered into two groups (nine patients were studied between five and 65 months, and two patients were studied 182 and 190 months after spinal cord injury; table 1).

As with statistical parametric mapping, absolute values of cerebral glucose consumption were adjusted to an arbitrary mean, we also determined the CMRGlu $(\mu \mathrm{mol} / 100 \mathrm{ml} /$ min) using elliptical regions of interest which were placed on the whole brain at the level of the thalamus and basal ganglia of the PET images transformed to the stereotactic atlas. ${ }^{12}$ Global metabolic rates of glucose for patients with spinal cord injury and healthy subjects were compared by Mann-Whitney $U$ test.

\section{Results}

Absolute global CMRGlu was significantly lower in patients with spinal cord injury than in healthy subjects $(33.6(6.6) \mu \mathrm{mol} / 100 \mathrm{ml} /$ $\min v 45.6(6.2) \mu \mathrm{mol} / 100 \mathrm{ml} / \mathrm{min}, P=$ 0.0026 , Mann-Whitney). The difference between drug treated ( $\mathrm{n}=8$, global CMRGlu $32 \cdot 6(8 \cdot 3)$ ) and untreated patients with spinal cord injury ( $\mathrm{n}=3$, global CMRGlu 35.4 (5.3) $\mu \mathrm{mol} / 100 \mathrm{ml} / \mathrm{min}$ ) was non-significant (Mann-Whitney $P=0 \cdot 8808$ ). This suggests that the global CMRGlu difference between patients with spinal cord injury and healthy subjects does not result from drug treatment.

Statistical parametric mapping disclosed pixels with relatively higher CMRGlu in the frontal lobe of patients with spinal cord injury, which bilaterally mainly comprised the supplementary motor area, and which caudally extended into the anterior cingulate (Brodman area 24), and more laterally towards the motor cortex. These differences were more pronounced at the left side of the brain. Also, a few pixels with relatively higher CMRGlu were disclosed bilaterally in the putamen (fig 1A). Circumscribed areas with relatively lower CMRGlu were found in the midbrain, cere-
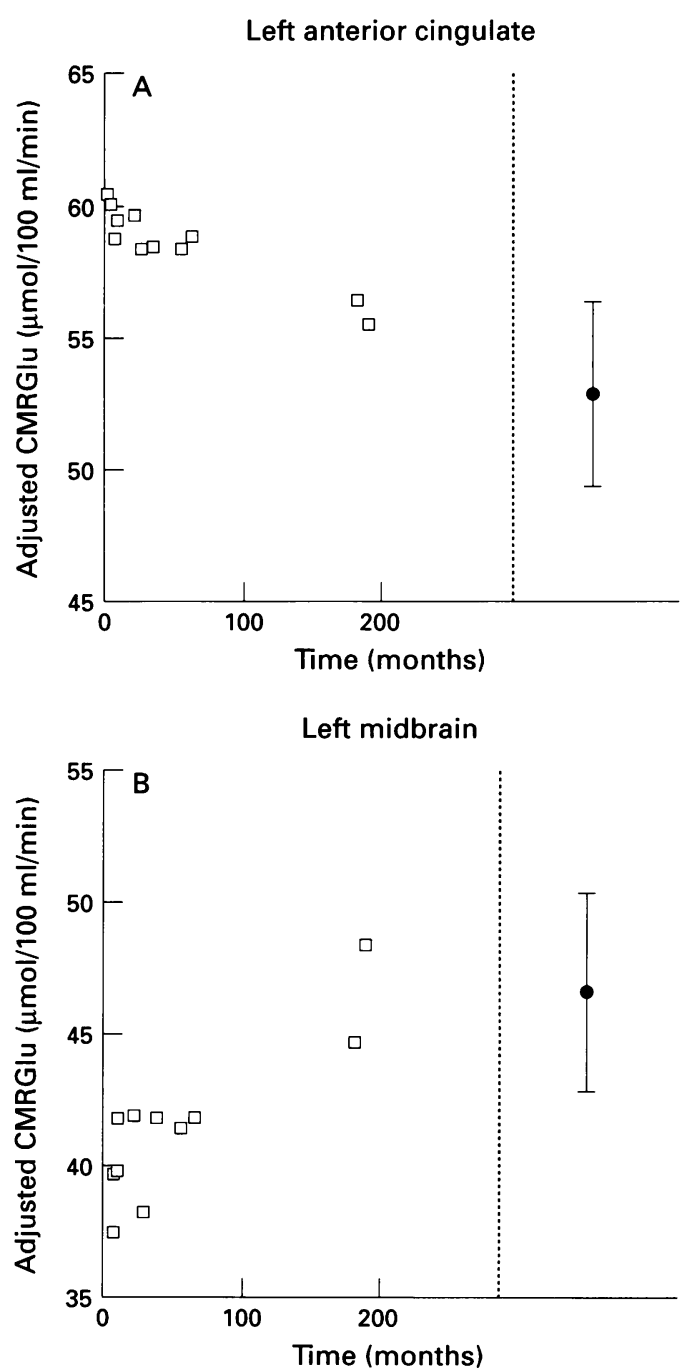

Figure 2 CMRGlu, adjusted to an arbitrary global mean (see methods), in the left anterior cingulate $(A)$ and midbrain (B) of patients with spinal cord injury (open squares) in relation to the time interval between spinal cord injury and PET study. For these regions, means (SD) of adjusted CMRGlu of healthy subjects are displayed at the right side of the plots (filled circle).

bellar hemispheres, and temporal cortex of patients with spinal cord injury (fig 1B). Table 2 lists the coordinates of peak differences. No differences between paraplegic and tetraplegic patients were found.

For the time interval between spinal cord injury and PET study, statistical parametric mapping analysis yielded decreasing CMRGlu values with time for the left anterior cingulate $(\mathrm{x} / \mathrm{y} / \mathrm{z}$ coordinates $-18 /+18 /+40, Z$ score $=$ 3.79) and left dorsal insular cortex ( $-34 /$ $-34 /+16, Z$ score $=3 \cdot 68)$. Figure $2 \mathrm{~A}$ shows this for the anterior cingulate. Increasing CMRGlu with time was found for the left $(-8 /-34 /-24, Z$ score $=3 \cdot 18)$ and right $(+8 /-32 /-28, Z$ score $=2.95)$ midbrain, as well as for the cerebellar vermis $(+4 /-60 /-8$, $Z$ score $=2 \cdot 66$ ). Figure $2 \mathrm{~B}$ shows this for the left midbrain.

\section{Discussion}

Our study shows a low absolute CMRGlu in resting patients with spinal cord injury. 
Because sensorimotor function comprising locomotion and sensory feed back from spinal cord to the brain in our patient group is expected to be greatly impaired or even absent, low CMRGlu may reflect a state of sensory deafferentiation and loss of pyramidal projections in these patients. Superimposed on the reduced global CMRGlu, our data disclose a distinct regional pattern of CMRGlu in patients with spinal cord injury which differs from that of healthy subjects. Patients with spinal cord injury at rest show relatively higher glucose metabolism in brain regions which are involved in movement preparation and execution, as well as in intentional aspects of motor tasks, particularly in the supplementary motor cortex, putamen, and anterior cingulate (Brodman area 32). In these regions, an increase in cerebral blood flow has been shown using PET and $\mathrm{H}_{2}{ }^{15} \mathrm{O}$ in healthy subjects during the performance of motor tasks. ${ }^{14}{ }^{15} \mathrm{Also}$, mental simulation of motor tasks or ideation of walking activates premotor cortical areas and basal ganglia. ${ }^{16}$ Therefore, patients with spinal cord injury, although partially or completely unable to move, show relative CMRGlu increases at rest in brain areas which are activated (according to blood flow measurement with PET) in healthy subjects before and during movement.

Given the coupling of regional CMRGlu and synaptic activity, ${ }^{8}$ relatively increased CMRGlu in the above mentioned regions of our patients could be attributed to overactivity of neurons which originate within, or which project to these regions. Accordingly, our results may reflect a relative disinhibition secondary to reduction or loss of afferent impulses-for example, from the spinal cord, thalamus, or parietal lobe. ${ }^{18}$ Neurophysiological experiments provide ample evidence that disinhibition mediates synaptic reorganisation. After sciatic nerve lesions in animals, early enlargement of receptive fields of the somatosensory cortex is attributed to a release of inhibition, ${ }^{19} 20$ and follows a characteristic time course. ${ }^{21}$ Similar results were obtained in human patients with spinal cord injury and in amputees. ${ }^{56}$ Likewise, during motor cortex reorganisation, the size of excitable motor areas increases after upper limb amputation. ${ }^{22}$ In addition, shoulder movement in subjects with traumatic upper limb amputation and phantom perception results in abnormal increases in blood flow in the primary somatosensory and posterior parietal cortex, which has also been attributed to a release of neurons from normal inhibitory control. ${ }^{23}$ Whereas these data were obtained through stimulation or movement and were recorded mainly from the primary motor or somatosensory cortex, the cortical differences between patients with spinal cord injury and healthy subjects in our study at rest were found in premotor areas. Whether these findings serve a clear functional role in patients with spinal cord injury remains open.

By contrast with the relatively increased glucose metabolism in brain regions which initiate movement, glucose metabolism in the cerebellum and midbrain was decreased. The cerebellum and certain midbrain relay nuclei participate in movement coordination and control. ${ }^{17}$ Accordingly, persisting impairment or absence of voluntary movement after spinal cord injury could explain reduced neuronal activity in these structures. In addition, our data suggest that abnormal CMRGlu shows a temporal correlation after spinal cord injury (fig 2). With increasing time from spinal cord injury, relatively high CMRGlu in the left anterior cingulate decreased, whereas relatively low CMRGlu in the brainstem increased, both regions approaching normal levels of relative CMRGlu. Whether these distinct time changes, which can be attributed to different aspects of movement (initiation, control), are generally present also in other parts of the motor system may be considered in a larger series of patients or in prospective studies.

Recovery from experimental spinal cord injury depends on the integrity of cerebral sensorimotor systems. Rats with spinal cord lesions show regeneration and anatomical plasticity of corticospinal neurons one to two months after treatment with antibodies neutralising myelin associated neurite growth inhibitory proteins. ${ }^{24}$ Contact placing of regenerating neurons in the spinal cord is, however, abolished after ablation of the sensorimotor cortex in these animals, which indicates that cortical neuronal activity is mandatory for recovery. ${ }^{24}$ Therefore, knowledge of the time course of regional cerebral activity after spinal cord injury in humans could have implications for a possible intervention once treatment regimens have developed.

This work was supported by the International Research Institute for Paraplegia (P16/93) and by the Swiss Bank Society on behalf of a client. We gratefully acknowledge the use of part of the statistical parametric mapping program, which was made available to us by the courtesy of $\mathrm{Dr} \mathrm{K} J$ Friston and Professor R S J Frackowiak, London, UK.

1 Ditunno JF, Young W, Donovan WH, Creasey G. The international standards booklet for neurological and functional classification of spinal cord injury. Paraplegic 1994;32:70-80.

2 Waters RL, Adkins RH, Yakura SJ, Sie I. Motor and sensory recovery following complete tetraplegia. Arch Phys Med Rehabil 1993;74:242-7.

3 Levy WJ, Amassian VE, Traad M, Cadwell J. Focal magnetic coil stimulation reveals motor cortical system reorganized in humans after traumatic quadriplegia. Brain Res 1990;510:130-4.

4 Topka H, Cohen LG, Cole RA, Hallett M. Reorganization of corticospinal pathways following spinal cord injury.

5 Song ZK, Cohen MJ, Ament PA, Ho WH, Vulpe M Schandler SL. Two-point discrimination thresholds in spinal cord injured patients with dysesthetic pain Paraplegia 1993;31:425-39.

6 Flor H, Elbert T, Knecht S, et al. Phantom-limb pain as a perceptual correlate of cortical reorganization following arm amputation. Nature 1995;375:482-4.

7 Yarowsky PJ, Ingvar DH. Neuronal activity and energy metabolism. Symposium summary. Fed Proc 1981;40: 2353-62.

8 Raichle ME, Grubb RL, Gabo MH, Eichling JO, TerPogossian MM. Correlation between regional cerebral blood flow and oxidative metabolism: in vivo studies in man. Arch Neurol 1976;33:523-6.

9 Baron JC. Depression of energy metabolism in distant brain structures: Studies with positron emission tomography in stroke patients. Sem Neurol 1989;9:281-5.

phy in stroke patients. Sem Neurol 1989;9:281-5.
10 Hamacher K, Coenen HH, Stöcklin G. Efficient stereospecific synthesis of no-carrier added $2-^{18} \mathrm{~F}$-fluoro-2-deoxycific synthesis of no-carrier added $2-^{-18}$ F-fluoro-2-deoxyD-glucose using aminopolyether supported

11 Rhodes CG, Wise RJS, Gibbs JM, et al. In vivo disturbance of the oxidative metabolism of glucose in human cerebral gliomas. Ann Neurol 1983;14:614-26. 
12 Talairach J, Tournoux P. Co-planar stereotaxic atlas of the human brain: Stuttgart: Thieme, 1988.

13 Friston KJ, Frith CD, Liddle PF, Frackowiak RSJ. Comparing functional (PET) images: the assessment of significant change. $\mathcal{f}$ Cerebr Blood Flow Metab 1991;11: 690-9.

14 Colebatch JG, Deiber MP, Passingham RE, Friston KJ, Frackowiak RS. Regional cerebral blood flow during voluntary arm and hand movements in human subjects. voluntary arm and hand moveme

15 Grafton ST, Woods RP, Mazziotta JC. Within-arm somatotopy in human motor areas determined by positron emission tomography imaging of cerebral blood flow. Exp

16 Roland PE, Eriksson L, Stone-Elander S, Widen L. Does mental activity change the oxidative metabolism of the brain? $\mathcal{F}$ Neurosci 1987;8:2373-89.

17 Ito $M$. The cerebellum and neural control: New York: Raven Press, 1984

18 Jones EG, Powell TPS. Anatomical organization of the somatosensory cortex. In: Iggo A, ed. Handbook of sensory physiology. Vol 2: somatosensory system. New York:
Springer, 1973: 572-620.

19 Calford $\mathrm{MB}$, Tweedale $\mathrm{R}$. Immediate and chronic changes in responses of somatosensory cortex in adult flying-fox after digit amputation. Nature 1988;332:446-8.

20 Dykes RW, Lamour Y. An electrophysiological laminar analysis of single somatosensory neurons in partially deafferentiated rat hindlimb granular cortex subsequent to transection of the sciatic nerve. Brain Res $1988 ; 449: 1-17$.

21 Cusick GC, Wall JT, Whiting JH, Wiley RG. Temporal progression of cortical reorganization following nerve injury, Brain Res 1990;537:335-58.

22 Cohen LG, Bandinelli S, Findeley TW, Hallett M. Motor reorganization after upper limb amputation in man. Brain 1991;114:615-27.

23 Kew JM, Ridding MC, Rothwell JC, et al. Reorganization of cortical blood flow and transcranial magnetic stimulation in human subjects after upper limb amputation. $f$ Neurophysiol 1994;72:2517-24.

24 Bregman BS, Kunkel-Bagden E, Schnell L, Ning Dai H, Gao D, Schwab ME. Recovery from spinal cord injury mediated by antibodies to neurite growth inhibitors. Nature 1995;378:498-501. 